\title{
SOBRE A NECESSIDADE DA MORAL NA DEMOCRACIA
}

\author{
Luan Fernandes Machado*
}

\begin{abstract}
Resumo: O propósito deste artigo consiste em sustentar a necessidade da moralidade formal na democracia. Para tanto, a moralidade formal é apresentada como uma consequência necessária caso queiramos uma democracia plural. Assim, o artigo elabora uma associação entre as três endemias da democracia liberal e o modelo agregativo de democracia, cujo pano de fundo é profundamente relativista, propondo, então, a adoção do modelo deliberativo. Em seguida, é apresentada a teoria agonística, segundo a qual o modelo deliberativo conduz ao ressurgimento da extrema direita ao sufocar a categoria ontológica do político. Contextualizando a discussão, o artigo desfaz a associação entre o ressurgimento da extrema direita e o deliberacionismo. A conclusão reforça a importância de se adotar a perspectiva do participante para analisar a democracia, incluindo-se aí o pano de fundo moral próprio deste regime, caso o queiramos plural.
\end{abstract}

Palavras-chave: Democracia liberal; Democracia deliberativa; Moral.

\section{ABOUT THE NEED FOR MORALS IN DEMOCRACY}

Abstract: The purpose of this article is to advocate the need for formal morality in democracy. For that, formal morality is presented as a necessary consequence if we want a plural democracy. Thereby, the article elaborates an association between the three endemics of liberal democracy and the aggregative model of democracy, whose background is deeply relativist, proposing, then, the adoption of the deliberative model. After, the agonistic theory is presented, according to which the deliberative model leads to the resurgence of the extreme right by suffocating the ontological category of the political. Contextualizing the discussion, the article undoes the association between the resurgence of the extreme right and deliberationism. The conclusion reinforces the importance of adopting the participant's perspective to analyze democracy, including the moral background of this regime, if we want it to be plural.

Keywords: Liberal democracy; Deliberative democracy; Moral.

\section{SOBRE LA NECESIDAD DE MORAL EN LA DEMOCRACIA}

Resumen: El propósito de este artículo es sustentar la necesidad de una moralidad formal en la democracia. Por eso, la moral formal se presenta como una consecuencia necesaria si queremos una democracia plural. Así, el artículo elabora una asociación entre las tres endémicas de la democracia liberal y el modelo agregativo de democracia, cuyo trasfondo es profundamente relativista, proponiendo, entonces, la adopción del modelo deliberativo. En seguida, se presenta la teoría agonística, según la cual el modelo deliberativo conduce al resurgimiento de la extrema derecha al sofocar la categoría ontológica de lo político. Contextualizando la discusión, el artículo deshace la asociación entre el resurgimiento de la extrema derecha y el deliberacionismo. La conclusión refuerza la importancia de adoptar la

\footnotetext{
* Graduando em Direito pela Universidade Federal do Rio de Janeiro (UFRJ), Brasil. Monitor bolsista de Teoria do Direito da Universidade Federal do Rio de Janeiro (UFRJ). ORCID: https://orcid.org/0000-0002-72521011. Contato: luanmachado.fm4@gmail.com.
} 
perspectiva del participante para analizar la democracia, incluyendo el trasfondo moral de este régimen, si queremos que sea plural.

Palabras clave: Democracia Liberal; Democracia deliberativa; Moral.

\section{Introdução}

Até as primárias das eleições dos presidenciáveis Joe Biden e Donald Trump, quase ninguém se arriscava a dizer que a democracia estadunidense estava a salvo. Já no Brasil, após as ameaças ao sistema eleitoral pelo presidente Jair Bolsonaro, não foram poucos os brasileiros que temeram um golpe.

Certamente este panorama nada tem a ver com as projeções dos cientistas políticos anteriores às turbulências mais imediatas da democracia liberal. Admitindo ou não, boa parte deles, como Fukuyama ${ }^{1}$, havia introjetado o fim da história em suas lentes teóricas. As utopias encontravam-se em crescente processo de extinção do imaginário político, refugiando-se, quando muito, para o imaginário cultural. A despeito das divergências quanto às políticas econômicas a serem adotadas, a democracia liberal, enquanto regime majoritário concorrencial com instituições contramajoritárias, parecia ser a receita de bolo para todos os países, contra os quais apenas os teoricamente marginalizados lutavam.

Por outro lado, em meio à crise, defender as promessas desta democracia virou um sinal de desatualização e ingenuidade. Uma das principias definidoras de tendências, a atual camada jovem da sociedade estadunidense possui a menor estima pela democracia desde décadas $^{2}$. Sintomática dessa desilusão é a recente distopia política Years and Years, ${ }^{3}$ cujo roteiro culmina na reeleição de Trump e numa Terceira Guerra Mundial.

De todo modo, em ambas, trata-se do mesmo comportamento natural dos humanos: imaginar que uma certa tendência que nos é contemporânea irá se intensificar gradativamente nos próximos tempos. $\mathrm{O}$ artigo, do contrário, almeja se distanciar desse comportamento natural. Ainda que compartilhe da preocupação da segunda tendência, entende que a proposta central do modelo deliberativo parece ainda mais necessária, contrapondo-se assim também à $1^{\mathrm{a}}$ tendência conformista. Diante deste auditório cínico em

\footnotetext{
${ }^{1}$ FUKUYAMA, F. O fim da História e o último homem. Trad. Aulyde S. Rodrigues. Rio de Janeiro: Rocco, 1992.

${ }^{2}$ MOUNK, Yascha. O povo contra a democracia: por que nossa liberdade corre perigo e como salvá-la. Trad. Cássio de Arantes Leite, Débora Landsberg. São Paulo: Companhia das Letras, 2019, p. 19-20.

${ }^{3}$ YEARS and Years. Direção: Lisa Mulcahy, Simon Cellan Jones. Produção: Russel T. Davies. Reino Unido e Irlanda do Norte: BBC One e HBO, 2019.
} 
relação a idealismos, em vez de provar a justeza do modelo, é preciso sustentar a necessidade deles. Para isso, pretendo trazer novas conclusões baseadas em uma revisão da literatura pertinente ao tema.

Na próxima sessão, exporei as endemias da democracia liberal. Nas duas sessões seguintes, imputo estas endemias à democracia liberal agregativa (2), propondo uma alternativa através da democracia deliberativa (3). Contra ambos os modelos, apresento as críticas do modelo agonístico (4), para então criticá-lo (5). Contextualizando o debate, sublinho o fato de que um dos principais diagnósticos da crise democrática não corrobora a tese agonística (6).

\section{Do excesso à falta de poder}

Desde o surgimento do Estado de Direito, ainda no séc. XVIII, já foram formulados desenhos institucionais a fim de que o poder fosse limitado. Como se sabe, com o princípio da legalidade, derivado do liberalismo político, as sociedades europeias substituíram o absolutismo, em que eram governadas tiranicamente, pelo Estado moderno, no qual passaram a ser governadas, em tese, por leis previamente estabelecidas, limitadas substantivamente pela Constituição. Em seguida, com a democratização do Estado de Direito, o poder também foi limitado através de sua fragmentação e difusão.

Conjugando ambos, a democracia liberal, por sua vez, é a tentativa de conciliar as qualidades substantivas do liberalismo político e as qualidades formais da democracia, ou seja, a proteção de liberdades individuais, de um lado, e a defesa da autodeterminação popular, de outro. Se o Estado de Direito impõe limites substantivos ao poder (proteção das liberdades individuais), o Estado Democrático o exige mais em termos formais ao reclamar legitimidade social (princípio majoritário). Desse modo, não me parece irrazoável dizer que as sociedades ocidentais vêm há bastante tempo dedicando-se a limitar o poder.

Ocorre que as democracias liberais vêm sofrendo com a carência de poder. Em Liberalismo e democracia, Bobbio pontua três causas principais para isso. Primeiramente, temos o excesso de input. De um lado, em virtude dos direitos individuais de liberdade política, de expressão, associação e de imprensa, os cidadãos possuem maior facilidade para demandar e pressionar o sistema político. De outro lado, os procedimentos cada vez mais exigentes de tomada de decisões devido aos vetos cruzados e aos tramites burocráticos obstam o poder de resposta do sistema político. Numa palavra: sobrecarga. 
Soma-se a isso o atrito constante derivado de uma sociedade plural. Como vivemos em democracias formais, isto é, em que são todos formalmente iguais independentemente de sua etnia, gênero, credo ou filiação, a chance de se cruzar com o Outro ${ }^{4}$ é muito maior do que numa democracia substantiva, em que os cidadãos são culturalmente homogêneos. ${ }^{5} \mathrm{~A}$ intensa conflituosidade daí advinda é tanta que relevantes teóricos como Schmitt ${ }^{6}$ defenderam que a homogeneidade social é conditio sine qua non e anterior à democracia formal.

Por último, Bobbio sublinha o fomento do atrito à segunda potência causado pela poliarquia. Diferentemente de uma autocracia, o poder encontra-se institucionalmente dividido em um regime democrático, seja pela tripartição dos poderes, seja pela proliferação dos órgãos de tomada majoritária de decisões. Consequentemente, criam-se centros de poder que muito provavelmente colidem entre si. Não à toa, uma parte considerável dos teóricos, diante desse quadro endêmico, acatou a democracia liberal apenas pela falta de opções que se apresentava pós-queda do muro de Berlim. Nem todos.

\title{
3 A fonte das endemias
}

Diante dessas aparentes contradições internas da democracia liberal, Habermas aduz que, em verdade, estas endemias são consequências de um modelo que pressupõe apenas um modo de agir humano: o agir instrumental. Nesse sentido, os humanos só regulariam suas ações através da relação meios-fins, cuja análise se reduz a ponderar quais meios são mais eficientes para atingir fins (interesses) sobre os quais não se discute.

\begin{abstract}
De acordo com esse modelo, os eleitores traduzem com seus votos um autointeresse mais ou menos esclarecido ao levantar pretensões diante do sistema político, enquanto os políticos, que querem obter ou manter cargos, trocam esses votos pelas ofertas de determinadas políticas. Da transação entre eleitores que fazem racionalmente escolhas e elites políticas resultam decisões que são racionais na medida em que levam em consideração os interesses agregados e simetricamente avaliados dos indivíduos. ${ }^{?}$
\end{abstract}

Nessa perspectiva, os indivíduos só seriam capazes de se agregar pelos interesses em comum. Sob a perspectiva da economia de mercado, é justificável que os indivíduos

\footnotetext{
${ }^{4}$ RIBEIRO, Djamila. O que é lugar de fala?. Belo Horizonte: Letramento, Justificando, 2017.

${ }^{5}$ BOBBIO, Norberto. Liberalismo e democracia. Trad. Marco Aurélio Nogueira. São Paulo: Brasiliense, 2000, p. 93.

6 "La igualdad democrática es, pues, una igualdad sustancial. Todos los ciudadanos pueden ser tratados como iguales, tener igualdad ante el sufragio, etc., porque participan de esa sustância". SCHMITT, Carl. Teoria de la Constituicíon. Trad. Francisco Ayala. Madri: Alianza Editorial, 1996, p. 225.

${ }^{7}$ HABERMAS, Jürgen. Facticidade e validade: contribuições para uma teoria discursiva do direito e da democracia. Trad. Felipe Gonçalves Silva, Rúrion Melo. São Paulo: Editora Unesp, 2020, p. 426.
} 
objetifiquem uns aos outros, isto é, vejam-se como meios para atingir seus interesses. Quando compramos uma mercadoria de um sujeito, não a compramos em termos solidários ponderando as circunstâncias pessoais (do sujeito), mas sim tendemos a levar em consideração a mercadoria (objeto). Instala-se o ambiente reificante.

Por sua vez, enquanto cidadãos, os indivíduos veriam o processo político da formação da opinião e da vontade com a mesma natureza do mercado. Isto porque, dentro do pressuposto por este modelo agregativo de sociedade, "suas decisões de voto têm a mesma estrutura dos seus atos de escolha orientados para o êxito dos participantes do mercado." Nos termos da teoria do sistema, "o input de votos e o output do poder seguem o mesmo padrão de ação estratégica", ${ }^{8}$ visto que selecionam os políticos a partir da compatibilização de interesses.

Este modelo, porém, é especialmente problemático quando analisamos, ceteris paribus, as consequências da dominação da esfera pública pelo agir estratégico. Caso os pressupostos antropológicos deste modelo estivessem corretos, segundo os quais a ação dos cidadãos é sempre egocêntrica, teríamos muitas dificuldades para explicar a estabilidade das sociedades, ainda que antidemocráticas:

\begin{abstract}
Pois, mesmo admitindo que o interesse aproxima os indivíduos, isso só poderia acontecer durante alguns instantes, uma vez que o laço que os une é exterior. $\mathrm{Na}$ troca, os diferentes portadores não se diluem uns nos outros, e quando o negócio é concluído cada um continua sendo ele mesmo, inteiramente senhor de si. Suas consciências se tocam apenas superficialmente, não se ligando, nem se entrelaçando. Quando olhamos mais fundo, descobrimos que a harmonia de interesses apenas encobre um conflito latente ou adiado. Entretanto, onde o interesse é o único dominador, todos estão em pé de guerra contra todos os outros, uma vez que não existe nada capaz de frear os egoísmos contrapostos e nenhum armistício conseguirá interromper por muito tempo essa eterna inimizade. $\mathrm{O}$ interesse é realmente a coisa mais instável no mundo. ${ }^{9}$
\end{abstract}

Diante dessas insuficiências teóricas, não é difícil vermos como o modelo agregativo conduziria às disfuncionalidades endêmicas da democracia liberal endossadas por Bobbio. Levando-se em consideração que os indivíduos possuem muitos interesses distintos uns dos outros, se os indivíduos se agregam somente com base em interesses, naturalmente serão formados infindáveis blocos de interesses e, consequentemente, apenas a escassa minoria deles restará atendida pelas instituições (sobrecarga). E já que a relação entre o sistema político e o povo torna-se apenas clientelista, a insatisfação tende a se generalizar.

\footnotetext{
${ }^{8}$ HABERMAS, Jürgen. A inclusão do outro: estudos de teoria política. Trad. Denilson Luís Werle. São Paulo: Ed. Unesp, 2018, p. 405.

${ }^{9}$ DURKHEIM, 1977, p. 257, apud HABERMAS, Jürgen. Teoria do agir comunicativo: sobre a crítica da razão funcionalista. Trad. Flávio Beno Siebeneichler. São Paulo: Editora WMF Martins Fontes, 2012, p. 212.
} 
Em segundo, tendo em conta que os indivíduos no modelo agregativo não são compelidos a incluir o Outro em sua visão de mundo egocêntrica, a objetificação de sujeitos cujas cosmopercepções sejam distintas conduziria a um ambiente insuportavelmente tóxico (atrito constante). Por consequência, o próprio sistema político também restaria hiperfragmentado e ancorado somente pela baixa "confiança inespecífica e altamente agregada da massa passiva de eleitores", ${ }^{10}$ conduzindo a um maior conflito entre as instâncias formais de tomada de decisões (atrito à segunda potência).

\begin{abstract}
Uma comunidade não pode se fragmentar na multiplicidade de suas subculturas, e penso que isso só pode ser permitido sob a condição de que todos os cidadãos possam se reconhecer numa única cultura política que transcenda as fronteiras de suas diversas subculturas. Para tanto, é preciso que a cultura política seja pelo menos um pouco separada das diversas subculturas. ${ }^{11}$
\end{abstract}

Por sinal, a origem primeira dessas insuficiências parece ser o relativismo moral ou "subjetivismo ético"12 impregnado neste modelo. Para se justificar decisões apenas com base no critério quantitativo da maioria, primeiro tem de se pressupor que todas as concepções morais possuem a mesma correção normativa. Daí termos o desprezo pela filosofia e, de forma mais geral, por qualquer discussão moral sobre os fins que devamos seguir enquanto sociedade. Ocorre que, mesmo que a democracia liberal seja procedimental a fim de respeitar a autonomia privada dos indivíduos, vedando-se hipostasiar politicamente um bem comum substantivo e imutável, não se extrai que ela precisa ser relativista no que tange à forma e ao fim dos seus procedimentos.

\title{
40 agir comunicativo como intersecção dos agregados
}

A partir das insuficiências das teorias objetivantes em explicar a estabilidade das sociedades, Habermas empreende um estudo antropológico pelo qual constata a existência de um outro tipo de racionalidade ou ação: a comunicativa. Ora, se o alto nível de organização política das sociedades não encontra explicação na produção material - em que hipoteticamente a maximização de interesses conduziria à estabilidade -, é porque há um elemento que está sendo negligenciado: a "moralização dos motivos de ação". ${ }^{13}$

\footnotetext{
${ }^{10}$ HABERMAS, Facticidade e validade, cit., p. 424-425.

${ }^{11}$ HABERMAS, Jürgen. A ética da discussão e a questão da verdade. Trad. Marcelo Brandão Cipolla. $4^{\mathrm{a}}$ ed. São Paulo: WMF Martins Fontes, 2018. p. 35-36.

${ }^{12}$ HABERMAS, Facticidade e validade, cit., p. 374.

${ }^{13}$ HABERMAS, Jürgen. Para a reconstrução do materialismo histórico. Trad. Carlos Nelson Coutinho. São Paulo: Editora Brasiliense, 1983, p. 117.
} 
A introdução de novas formas de integração social - como, por exemplo a substituição do sistema de parentesco pelo Estado - requer um saber de tipo prático-moral, não um saber tecnicamente valorizável, que possa ser traduzido e implementado em regras de agir instrumental e estratégico. Ela requer não uma ampliação de nosso controle sobre a natureza externa, mas um saber que que possa se encarnar em estruturas de interação: em poucas palavras, uma ampliação da autonomia social em face de nossa própria natureza interna. ${ }^{14}$

O agir comunicativo é necessário quando um certo "ator só pode executar o seu plano de ação de modo interativo, isto é, com o auxílio (ou mediante a omissão de auxílio) de pelo menos um outro autor", e pretende, para tanto, retirar da própria “força consensual do entendimento linguístico" 15 um acordo entre os planos de ação individuais. Diferentemente, pelo agir instrumental, ainda que haja uso da linguagem entre os atores, a coordenação não brota do entendimento linguístico, mas da dissimetria interna entre os atores (influência de um sobre o outro) ou externa (maior controle da situação por um).

Alimentando-se deste potencial emancipatório do agir comunicativo, Habermas propõe, então, a democracia dialógica ou deliberativa. No modelo agregativo, as decisões políticas são apenas quantitativamente democráticas, válidas pela origem, isto é, por descenderem da maioria (ad hominem). Já a democracia deliberativa preconiza que as decisões políticas também o sejam qualitativamente democráticas, válidas por brotarem de deliberações perpassadas por procedimentos diante dos quais os parlamentares, p. ex., são constrangidos institucionalmente a deliberar em termos criticáveis e a deixar-se afetar pelas razões contrapostas, a fim se de construir um entendimento intersubjetivo.

Sendo assim, a radicalização da democracia ocorre pela institucionalização e difusão da ética do discurso, cujos atores se comprometem a incluir o Outro na sua compreensão egocêntrica do tema, coibindo a colonização da esfera pública pela razão instrumental, já que não se visa a um fim predeterminado, mas a cooperação discursiva:

Uma solução de acordo com a qual o princípio ético envolvido na prática democrática estaria relacionado à qualidade dos processos de comunicação ligados à democracia. Ao transitar do campo das éticas substantivas para o campo das éticas formais, a teoria habermasiana nos permite restabelecer uma relação entre democracia, ética e bem comum, de acordo com a qual o bem comum estaria ligado às regras utilizadas pelos participantes na prática da democracia. ${ }^{16}$

\footnotetext{
${ }^{14}$ HABERMAS, Para a reconstrução do materialismo histórico, cit., p. 126.

${ }^{15}$ HABERMAS, Jürgen. Pensamento pós-metafísico: estudos filosóficos. Trad. Flávio Beno Siebeneichler. Rio de Janeiro: Tempo Brasileiro, 1990, p. 71.

${ }^{16}$ AVRITZER, Leonardo. A moralidade da democracia: ensaios em teoria habermasiana e teoria democrática. São Paulo: Perspectiva; Belo Horizonte: Editora da UFMG, 1996, p. 21-22.
} 
A existência fática de um outro tipo de razão, denominada comunicativa, consiste no fundamento com base no qual Habermas propôs a política deliberativa. O entendimento comum constitui-se, então, em um ideal regulador da crítica e do aperfeiçoamento argumentativos das normas e acordos sociais facticamente vigentes. Não se trata, dessa maneira, de um ideal descolado da realidade, mas nela ancorado.

Com isso, a democracia deliberativa enfrentaria as três endemias presentes no modelo agregativo de democracia liberal. Quanto à sobrecarga, a procedimentalização da ética do discurso conduziria a uma maior uniformidade de demandas ao final das deliberações ou, subsidiariamente, a uma legitimidade social devido à coautoria das leis mediante a inclusão discursiva de seus destinatários. $\mathrm{O}$ atrito constante também seria suavizado, uma vez que, devido à adesão institucional à ética do discurso, o vínculo em comum baseado em uma moral formal verdadeiramente democrática seria fomentado. Por último, os conflitos à segunda potência seriam menos frequentes pela derrocada da relação clientelista entre o sistema político e os cidadãos.

\section{A baixa tensão da democracia deliberativa}

Ocorre que, se as consequências da fragmentação moral se mostraram pouco factíveis, em Sobre o político (2015), o ponto de partida de Mouffe consiste em mostrar que a crise atual das democracias advém da resistência de teóricos como Habermas em lidar com os problemas políticos de forma política, e não moral. Desse modo, as consequências da democracia deliberativa seriam antidemocráticas.

Primeiramente, para a autora, o "político" seria ontologicamente a "dimensão de antagonismo" constitutiva das sociedades humanas, enquanto a política seria onticamente o "conjunto de práticas e instituições por meio das quais uma ordem é criada, organizando a coexistência humana no contexto conflituoso produzido pelo político”.

A partir dessa distinção conceitual entre a categoria universal do "político" e o modo histórico como ela se concretiza na realidade (política), Mouffe defende que a política não pode represar o "político", isto é, ignorar a sua conflituosidade inerente, sem que, a longo prazo, a própria política fique sob ameaça. Consequentemente, "a especificidade da política democrática não é a superação do nós/eles, mas a forma diferente pela qual ela se 
estabelece"17. Afinal, valendo-se de Schmitt, a autora aduz que "o político faz parte da nossa condição ontológica"18.

Diante da impossibilidade de se superar a conflituosidade e a formação de identidades coletivas a partir da dicotomia nós/eles, a democracia deve ter como singularidade a domesticação do antagonismo por uma "relação nós/eles em que as partes conflitantes, embora reconhecendo que não existe nenhuma solução racional para o conflito, ainda assim reconhecem a legitimidade de seus oponentes”19. A essa relação, Mouffe dá o nome de agonismo, contrapondo-a ao antidemocrático antagonismo.

Por sua vez, o reconhecimento de legitimidade só pode se dar pela "existência de um espaço simbólico em comum" ${ }^{20}$, e não por uma racionalidade a priori. Diferentemente da formulação, ancorada em princípios morais, de procedimentos para discussão, Mouffe sugere "um consenso conflituoso" pelo qual o "traçado da fronteira entre o legítimo e o ilegítimo é sempre uma decisão política e que, portanto, ela deve estar sempre sujeita à contestação"21.

Dito isto, a perspectiva agonista não acredita na força agregadora da moral inclusiva. A formação de identidades coletivas deve ser canalizada não pela deliberação moral ou pelo cálculo racional de interesses, aos quais ela relaciona os modelos deliberativo e agregativo, mas primacialmente pelo papel das paixões. Assentando-se também em Freud, a autora sustenta que é possível manter unidos os grupos nós/eles desde que por laços afetivos. Para controlar os instintos agressivos inerentes à natureza humana, é necessário construir laços comunitários.

Assim sendo, ao absorver o político em suas estruturas, uma democracia agonística tanto suavizaria o antagonismo ontológico da sociedade, quanto se distinguiria da democracia deliberativa, cujos representantes acabam por instigar o antagonismo. Isto porque, ao visar o consenso e transformar o conflito entre "direita e esquerda" em "correto e errado" ou "bem e mal", Rawls e Habermas formulam um projeto mais excludente do que o proposto por bases tecnocratas.

\footnotetext{
${ }^{17}$ MOUFFE, Chantal. Sobre o político. Trad. Fernando Santos. São Paulo: Editora WMF Martins Fontes, 2015. p. 13.

${ }^{18}$ Ibidem, p. 15.

${ }^{19}$ Ibidem, p. 19.

${ }^{20}$ Ibidem, p. 121.

${ }^{21}$ Idem.
} 
Ora, quando, em vez de ser formulado como um confronto político entre "adversários, o confronto nós/eles é visto como um confronto moral entre o bem e o mal, o oponente só pode ser percebido como um inimigo a ser destruído, e isso não favorece um tratamento agonístico. ${ }^{22}$

Como sinalizado, as consequências do deliberacionismo levariam, ato contínuo, ao crescimento do populismo de direita, movimento antidemocrático que é. Visto que as fronteiras políticas entre direita e esquerda vão sendo apagadas, o político, impedido de entrar nos canais políticos legítimos, penetra pela válvula de escape dos demagogos de direita, qual seja, o discurso anti-establishment.

Quando examinamos o estado da política democrática em todos os países em que o populismo de direita fez grandes progressos, encontramos uma semelhança impactante. Seu crescimento sempre ocorreu numa situação em que as diferenças entre os partidos democráticos tradicionais se tornaram muito menos significativas do que eram antes. [...] havia se estabelecido um consenso no centro que não permitiu que os eleitores fizessem uma escolha real entre políticas significativamente diferentes. ${ }^{23}$

Em suma, o seu argumento central gira em torno do que eu denominei de baixa tensão da democracia deliberativa. Ao tentar diminuir o choque de identidades coletivas através de uma postura inclusiva e aberta, as fronteiras entre os polos se desfazem e a tensão intrassistêmica diminui, daí sua baixa intensidade. Contudo, por via transversa, o político se refugiaria através da oposição establishment e outsider. Segundo a autora, a paixão derivada do conflito é necessária, sem ela a sociedade adoece.

\section{$6 \mathrm{O}$ retorno à objetificação dos sujeitos}

As críticas de Mouffe à teoria deliberativa representam, desta vez pela ala progressista da esquerda, o retorno da visão objetivante sobre os sujeitos. Enquanto no agregacionismo os humanos são objetos de interesses derivados do mercado, no agonismo nós somos vistos como reféns de nossas emoções. Ambos se alimentam de uma visão hobbesiana do humano. O mais revelador é que, a despeito do pretenso realismo, as duas teorias também possuem um ideal: o ideal normativo de uma sociedade sem ideais normativos. Assim como foi demonstrado em relação ao agregacionismo, o agonismo é insustentável, ao menos nas sociedades pós-convencionais, cujos membros adotam normas por reflexão, e não por convenções.

\footnotetext{
${ }^{22}$ MOUFFE, Chantal. Por um modelo agonístico de democracia. Curitiba; Revista de Sociologia e Política, 2006, p. 5.

${ }^{23}$ MOUFFE, Sobre o político, cit., p. 67.
} 
Como exposto, a autora vale-se da teoria freudiana para afirmar que a única via pela qual é possível criar um vínculo entre os dois polos de modo a conter os instintos agressivos é a criação de laços afetivos, ou seja, a via emocional. Ocorre que a sua interpretação da teoria freudiana pode ser contestada:

\begin{abstract}
O outro método que Freud propôs, a substituição do instinto pelo intelecto, mais do que pressupor uma sociedade de homens iguais, conduz a ela. Pois é uma idéia lançada por Freud, embora nunca desenvolvida, que no futuro, um ideal, mais especificamente o ideal da razão, poderá desempenhar o papel que, nas sociedades mais tradicionais, é preenchido pelo líder. [...]

Freud acreditava na razão. Em O futuro de uma ilusão, escreveu: 'A longo prazo, nada pode resistir à razão e à experiência. Quer dizer, Freud acreditava que a mente de um homem está organizada de tal modo que pode ser influenciada por argumentos e considerações racionais, desde que se disponha a ouvi-los. ${ }^{24}$
\end{abstract}

Quanto aos pressupostos da democracia deliberativa, primeiramente Habermas inspira-se historicamente nas suas análises sobre as origens e implicações da mudança estrutural da esfera pública a partir do século XVII. A cisão entre privacidade e autoridade proporciona um ambiente fértil para o agir comunicativo. ${ }^{25} \mathrm{~A}$ autoridade é publicizada, em detrimento da antiga fronteira entre sagrado (público) e profano (privado). Funda-se uma "espécie de paridade entre os homens da sociedade aristocrática e da intelectualidade burguesa." ${ }^{26}$ Nas coffee houses, eles encontram um espaço público - já que mais aberto e com suposição de igualdade de status -, em que discutem através de obras literárias sobre temas essenciais para sua autocompreensão, de sorte que a única autoridade subsistente é a do argumento (ad rem).

Sobre o fenômeno de inclusão discursiva do Outro, Habermas, inspirando-se nos estudos do psicólogo Kohlberg, sustenta que, com a mudança gradativa das sociedades convencionais para as pós-convencionais, a legitimidade das normas passa a encontrar seu fundamento na autonomia. Enquanto naquelas o Direito retira sua legitimidade da compatibilização substantiva de seu conteúdo com as éticas religiosas, a partir da secularização o Direito torna-se formalmente legítimo se e na medida em que os procedimentos de produção de normas transparecem ancorar-se na soberania popular.

\footnotetext{
${ }^{24}$ WOLLHEIM, Richard. As ideias de Freud. Trad. Álvaro Cabral. São Paulo: Círculo do Livro, 1971, p. 253. ${ }^{25}$ AVRITZER, A moralidade da democracia, cit., p. 32.

${ }^{26}$ HABERMAS, Jürgen. Mudança estrutural da esfera pública: investigações quanto a uma categoria da sociedade burguesa. Trad. Flávio R. Kothe. $2^{a}$ ed. Rio de Janeiro: Tempo Brasileiro, 2013, p. 48.
} 
Como a marca da contemporaneidade é a globalização, a moral deve ser pensada em termos pós-convencionais, pois não pode estar entrelaçada com nenhuma forma de vida particular para sustentar um concepção de justiça universal. Somente a partir de um ponto de vista pós-convencional a moral poderá ser compreendida como um meio de integração social numa sociedade cosmopolita, em que a inclusão, de modo não niveladora e não discriminatória, do outro é um dever. Isto se traduz numa moral do respeito, que não apaga nossas diferenças, e da responsabilidade solidária por cada um. ${ }^{27}$

Diante disto, parece anacrônica a defesa de Mouffe sobre a necessidade do elemento passional. Afinal, caso os pressupostos psicológicos da teoria de Mouffe estiverem corretos, os partidos políticos teriam que empreender discursos cada vez mais passionais a fim de aglutinar indivíduos carentes de identidades coletivas, sob pena de incorrer nas consequências da fragmentação (vide seção 2). Se do ponto de vista das elites políticas isso pode parecer possível, quando analisamos esta conjectura do ponto de vista interno dos participantes (cidadãos) há sérias dificuldades.

O público de cidadãos dificilmente seria levado a participar do processo democrático, ou ao menos de aceitá-lo de maneira benevolente, enquanto fosse considerado apenas vítima político-ideológica dos partidos concorrentes. Ele quer poder ser convencido de que a ascensão ao governo por um dos partidos significa a expectativa de melhores políticos em comparação com os de um outro partido em geral, é preciso haver boas razões para preferir um partido em detrimento de outro. Com isso, alcançamos, afinal, o ponto no qual aquilo que é evidente da perspectiva do observador não se deixa mais traduzir em razões que sejam igualmente evidentes para os participantes. [...] Como previsto, a visão objetivante não permite perceber uma dimensão de validade na luta pelo poder entre os partidos políticos. ${ }^{28}$

Em contextos pós-convencionais, os regimes políticos não parecem se sustentar a longo prazo pela identidade entre um líder e um povo. Justamente por isso, a política deliberativa consegue sua legitimidade a partir da "expectativa da qualidade racional de seus resultados" ${ }^{29}$ gerada pela formação discursiva da opinião e da vontade. Isto porque a inclusão discursiva do Outro dá traços de imparcialidade e consequentemente racionalidade ao processo legiferante.

Em síntese, a alta tensão, derivada do agonismo de identidades coletivas verdadeiramente contrapostas, não é mais uma necessidade para o sujeito pós-convencional, categoria cada vez mais presente ${ }^{30}$. Do contrário, este sente a necessidade de se considerar

\footnotetext{
${ }^{27}$ SANTOS, Fábio Eulalio. A fundamentação da moral em Jürgen Habermas. Belo Horizonte: Universidade Federal de Minas Gerais, Faculdade de Filosofia e Ciências Humanas, 2007 (Dissertação, Mestrado em Filosofia), p. 11.

${ }^{28}$ HABERMAS, Facticidade e validade, cit., p. 376.

${ }^{29}$ Ibidem, p. 389.

${ }^{30}$ A este respeito, conferir o processo de secularização descrito por Paiva: "1900 a 1970 os agnósticos multiplicaram-se 181 vezes, os ateus 720 vezes, e os crentes das religiões históricas apenas cerca de 3 vezes"
} 
livre, isto é, capaz de tomar uma atitude sem que esteja sendo coagido por fatores sobre os quais não possui controle, como uma deidade ou a paixão. Para tanto, no âmbito privado, o sujeito pós-convencional promulga normas para si próprio, sentindo-se livre quando as segue ainda que sob influência de fatores do mundo sensível, autossuperando-se, ${ }^{31}$ já no âmbito público, ele precisa pressupor que as decisões políticas são formadas racionalmente, e esta pressuposição torna-se mais verossimilhante quando os procedimentos institucionais constrangem os legisladores a deliberar pela ética do discurso. Com isso, a decisão que poderia ser vista como heterônima e causar repulsa, passa a ser recebida como autônoma, já que produto da inclusão discursiva de todos os seus possíveis destinatários, sendo considerada legítima e emancipatória.

\section{Fatores exógenos}

Diante da última sessão, as tentativas agregacionista e agonista de refutar a necessidade de fundamentação moral da democracia não se mantiveram tão firmes. A exposição da democracia deliberativa, por sua vez, foi ganhando contornos antropológicos, psicológicos e históricos. Admitindo que as críticas de Mouffe ao modelo de Habermas não conseguem explicar as crises da democracia no último decênio, podemos tentar analisar estas crises adotando uma perspectiva em certa medida externa ao debate dos modelos até agora vistos, a fim de desfazer a associação precipitada de Mouffe entre as crises e o ressurgimento da extrema direita e o modelo deliberativo.

Na recente obra O povo contra a democracia (2019), Mounk alinha que as origens das crises da democracia liberal encontram-se subdivididas em três fatores: as mídias sociais, a estagnação econômica e os choques identitários. São, pois, questões exógenas à democracia deliberativa, fora um adendo em relação à pluralidade identitária.

Na esteira do que já se expôs, a divisão da sociedade em rebanhos parece ser prejudicial à democracia liberal. As mídias sociais, porém, são um potente construtor de cercas. A despeito das muitas expectativas depositadas na democratização da produção de conteúdo, as mídias sociais têm possibilitado a difusão de fake news e a fragmentação da

(PAIVA, J. (Org). Entre necessidade e desejo: diálogos da psicologia com a religião. São Paulo: Loyola, 2001, p. 77). Ainda que o ateísmo, ou até agnosticismo, não signifique, de modo algum, mentalidade pósconvencional, e vice-versa, é razoável associar este processo de secularização ao gradativo anseio por autodeterminação moral, deixando-se de se recorrer a figuras transcendentais ou metafísicas para justificar suas condutas e ideais.

${ }^{31}$ KANT, Immanuel. Metafísica dos costumes. Trad. Clélia Aparecida Martins, Bruno Nadai, Diego Kosbiau, Monique Hulshof. Petrópolis, RJ: Vozes; Bragança Paulista, SP: Ed. Universitária São Francisco, 2013, p. 32. 
sociedade em acirradas bolhas. Diferentemente da comunicação "um-para-muitos," cujo conteúdo é produzido e distribuído por um pequeno grupo de grandes canais de mídia a um número muito maior de destinatários, a "comunicação muitos-para-muitos"32 aumenta o contingente de produtores de conteúdo e difusores de informação.

Em princípio, a democratização da produção e difusão de conteúdo pode parecer até mesmo propícia à democracia. Contudo, com menos regulação, a circulação de fake news aumenta, e consequentemente o diálogo democrático fica comprometido em virtude da desinformação. Soma-se a isso, o fato possivelmente surpreendente de que, para muitas pessoas, a grande pluralidade de conteúdos e informações divergentes, em vez de propiciar uma mentalidade descentralizada, crítica e aberta, fomentou o ímpeto para se refugiar naquilo que Sunstein chamou de "câmaras de eco". 33

Seguindo nessa esteira, a tese da necessidade de identidades coletivas parece ser endossada. Quando ainda no início do uso de rede sociais, a maioria dos usuários se abrem a outras bolhas tanto intencionalmente, seguindo a curiosidade de conhecer a rede, quanto por falta de conhecimento sobre quais são os influencers simpáticos a seu ethos, o que os leva, mediante tentativa e erro, a se defrontarem com o Outro. Em seguida, não tarda para que boa parte dos usuários sejam aglutinados em um nicho de mercado e cosmovisões. Porém, este processo não se deve aos usuários das redes, mas primacialmente aos algoritmos ${ }^{34}$. A este respeito, é reveladora a exaustão a que está chegando esse modelo de rede social, tendo em vista a crescente crítica dos usuários.

Em segundo, por um bom tempo o imaginário social associou democracia à diminuição da desigualdade social ou melhora na qualidade de vida. Entendia-se que, com a necessidade de agradar também os setores mais desprivilegiados, os governos democráticos teriam de diminuir a desigualdade. Historicamente, esta correlação até conseguiu se mostrar em parte correta, sobretudo se analisarmos o período do pós-guerra. ${ }^{35}$ Porém, desde a década de 80 para os países desenvolvidos, e desde a última década para os subdesenvolvidos, a economia dos regimes democráticos está estagnada, com poucas taxas de crescimento e de

\footnotetext{
${ }^{32}$ MOUNK, O povo contra a democracia, cit., p. 173.

${ }^{33}$ SUNSTEIN, Cass. Republic.com 2.0. Princeton: Princeton University Press, 2009 apud MOUNK, O povo contra a democracia, cit., p. 172.

${ }^{34}$ A este respeito, Santaella aduz que os filter bubbles "conduzem o usuário a pontos de vista estreitos que impedem a exposição a ideias contrárias a seus preconceitos" (SANTAELLA, Lucia. A pós-verdade é verdadeira ou falsa? São Paulo: Estação das Letras e Cores, 2018, p. 17.)

${ }^{35}$ PIKETTY, Thomas. O capital no século XXI. Trad. Monica Baumgarten de Bolle. Rio de Janeiro: Intrínseca, 2014, p. 284 e 319.
} 
igualdade $^{36}$, limitando a possibilidade, tipicamente democrática, de ascensão social e amedrontando os cidadãos em relação ao seu futuro no mercado de trabalho. Consequentemente, o imaginário social é frustrado, sentimento canalizado pela extrema direita, conforme nos ensinam os exemplos históricos.

Mounk ainda destaca como a crescente imigração tem contribuído para o descrédito da democracia liberal. Embora seja constituinte da democracia liberal a pluralidade, o aumento da imigração em regiões provincianas, desacostumadas a lidar com hábitos distintos, intensifica o atrito constante. Novamente a teoria de Mouffe parece estar correta. Mas, para o nosso bem, pesquisas apontam que o preconceito por parte dos grupos hegemônicos tende a arrefecer diante do contato regular com os grupos minoritários - o que sublinha a precipitação da autora. ${ }^{37}$

Soma-se a estas três questões exógenas, a metamorfose da democracia liberal em tecnocracia liberal. O governo por pessoa comuns, como já anunciava Bobbio ${ }^{38}$, parece ser tanto mais inevitável quanto mais os problemas políticos parecem requerer competências técnicas. O governo dos técnicos (tribunais, agências reguladoras e bancos centrais) não é, desse modo, uma endemia da democracia deliberativa, mas também é uma questão exógena derivada da complexificação da sociedade de massas. Por sua vez, este fato só nos incomoda devido à nossa necessidade por nos sentirmos livres.

\section{Conclusão: uma pequena moeda num grande jarro vazio}

Do exposto, entendo que a democracia liberal-deliberativa tem muitos desafios. Mas, ao que tudo indica, as suas adversidades são originadas de vetores exógenos ao modelo deliberativo, a saber, a recessão econômica, o aumento da imigração em regiões provincianas, a tecnocracia e o fenômeno das mídias sociais. No momento, as críticas à necessidade da moral democrática e a associação entre o ressurgimento da extrema direita e a democracia deliberativa parecem precipitadas.

Mesmo que as crises por qual passaram ou ainda passam as democracias liberais sejam relevantes, os últimos tempos só puderam ser categorizados assertivamente como uma crise devido à difusão dos potenciais normativos do modelo deliberativo. É somente pela perspectiva do participante que torna razoável conceber como crise uma década sem grandes

\footnotetext{
${ }^{36}$ PIKETTY, O capital no século XXI, cit., p. 347.

${ }^{37}$ MOUNK, O povo contra a democracia, cit., p. 213.

${ }^{38}$ BOBBIO, Norberto. O futuro da democracia: uma defesa das regras do jogo. Trad. Marco Aurélio Nogueira. $6^{\mathrm{a}}$ ed. Rio de Janeiro: Paz e Terra, 1986, p. 33.
} 
guerras. Um observador extemporâneo teria dificuldades em enquadrar o último decênio como uma crise ao comparar com outros períodos significativamente mais turbulentos para a democracia. Aliás, também não se pode perder de vista que, ao lado do aumento dos discursos de ódio, existe um aumento correspondente da demanda por diálogos racionais e inclusivos $^{39}$, o que torna mais uma vez questionável o descarte precipitado da ética do discurso.

Por outro lado, se depois destas poucas linhas foi possível cogitar pragmaticamente alguma conclusão, tanto melhor se o foi sobre o passado, e não sobre o inarredavelmente imprevisível futuro. Esta conclusão, arrisco dizer, consiste em que, apesar de não ser mais possível defender o diagnóstico habermasiano na sua integridade devido aos fatores exógenos listados, a defesa da moral na democracia ainda permanece como um ideal central.

\footnotetext{
39 A título de exemplos, não parece haver dúvidas sobre a reação negativa de uma parte significativa dos brasileiros sobre o desrespeitoso debate entre então presidenciáveis estadunidenses, tampouco acerca da cobrança de que o então candidato à Presidência Jair Bolsonaro fosse aos debates. Já nas redes, há o sucesso da advogada Gabriela Priolli, cujo mote reiterado nos vídeos é "mais razão e menos emoção".
} 


\section{Referências Bibliográficas}

ALMEIDA, Philippe Oliveira de. Crítica da razão antiutópica: inovação institucional na aurora do Estado Moderno. Belo Horizonte: Universidade Federal de Minas Gerais, Faculdade de Direito, 2016 (Tese, Doutorado em Direito).

AVRITZER, Leonardo. A moralidade da democracia: ensaios em teoria habermasiana e teoria democrática. São Paulo: Perspectiva; Belo Horizonte: Editora da UFMG, 1996.

BOBBIO, Norberto. Liberalismo e democracia. Trad. Marco Aurélio Nogueira. São Paulo: Brasiliense, 2000.

BOBBIO, Norberto. O futuro da democracia: uma defesa das regras do jogo. Trad. Marco Aurélio Nogueira. Rio de Janeiro: Paz e Terra, 1986.

CARVALHO NETTO, Menelick de; SCOTTI, Guilherme. Os direitos fundamentais e a (in)certeza do Direito: a produtividade das tensões principiológicas e a superação do sistema de regras. $2^{\mathrm{a}}$ ed. rev. Belo Horizonte: Fórum, 2020.

COELHO, André L. S. Facticidade e Validade no Processo Judicial. Não publicado. Disponível em: https://www.academia.edu/4435632/Facticidade_e_Validade_no_Processo_Judicial.

CONSTANT, Benjamin. A liberdade dos antigos comparada à dos modernos: discurso pronunciado no Ateneu Real de Paris em 1819. São Paulo: Edipro, 2019.

HABERMAS, Jürgen. A ética da discussão e a questão da verdade. Trad. Marcelo Brandão Cipolla. $4^{a}$ ed. São Paulo: WMF Martins Fontes, 2018.

HABERMAS, Jürgen. A inclusão do outro: estudos de teoria política. Trad. Denilson Luis Werle. São Paulo: Ed. Unesp, 2018.

HABERMAS, Jürgen. Facticidade e validade: contribuições para uma teoria discursiva do direito e da democracia. Trad. Felipe Gonçalves Silva, Rúrion Melo. São Paulo: Editora Unesp, 2020.

HABERMAS, Jürgen. Mudança estrutural da esfera pública: investigações quanto a uma categoria da sociedade burguesa. Trad. Flávio R. Kothe $2^{\mathrm{a}}$ ed. Rio de Janeiro: Tempo Brasileiro, 2013.

HABERMAS, Jürgen. Para a reconstrução do materialismo histórico. Trad. Carlos Nelson Coutinho. São Paulo: Editora Brasiliense, 1983.

HABERMAS, Jürgen. Pensamento pós-metafísico: estudos filosóficos. Trad. Flávio Beno Siebeneichler. Rio de Janeiro: Tempo Brasileiro, 1990.

HABERMAS, Jürgen. Teoria do agir comunicativo: sobre a crítica da razão funcionalista. Trad. Flávio Beno Siebeneichler. São Paulo: Editora WMF Martins Fontes, 2012.

KAHN, Michael. Freud básico: pensamentos psicanalíticos para o século XXI. Trad. Luis Paulo Guanabara. $4^{\mathrm{a}}$ ed. Rio de Janeiro: BestBolso, 2018.

KANT, Immanuel. Metafísica dos costumes. Trad. Clélia Aparecida Martins, Bruno Nadai, Diego Kosbiau, Monique Hulshof. Petrópolis, RJ: Vozes; Bragança Paulista, SP: Ed. Universitária São Francisco, 2013.

KELSEN, Hans. A democracia. Trad. Vera Barkov, Jefferson Luiz Camargo, Marcelo Brandão Cipolla. Ivone Castilho Benedetti. $3^{\mathrm{a}}$ ed. São Paulo: Editora WMF Martins Fontes, 2019.

LEVITSKY, Steven; ZIBLATT, Daniel. Como as democracias morrem. Trad. Renato Aguiar. Rio de Janeiro: Zahar, 2018.

MIGUEL, Luis Felipe. Consenso e conflito na teoria democrática: para além do "agonismo". São Paulo: Lua Nova, 2014. Disponível em: https://doi.org/10.1590/S010264452014000200002.

MOUFFE, Chantal. Sobre o político. Trad. Fernando Santos. São Paulo: Editora WMF Martins Fontes, 2015. 
MOUFFE, Chantall. Por um modelo agonístico de democracia. Trad. Pablo Sanges Ghetti; Gustavo Biscaia de Lacerda. Curitiba; Revista de Sociologia e Política, $\mathrm{n}^{\circ} 25$ : 165-175 JUN. 2006. Disponível em: https://doi.org/10.1590/S0104-44782005000200003.

MOUNK, Yascha. O povo contra a democracia: por que nossa liberdade corre perigo e como salvá-la. Trad. Cássio de Arantes Leite, Débora Landsberg. São Paulo: Companhia das Letras, 2019.

PAIVA, J. (Org). Entre necessidade e desejo: diálogos da psicologia com a religião. São Paulo: Loyola, 2001.

PIKETTY, Thomas. O capital no século XXI. Trad. Monica Baumgarten de Bolle. Rio de Janeiro: Intrínseca, 2014.

RIBEIRO, Djamila. O que é lugar de fala?. Belo Horizonte: Letramento, Justificando, 2017.

SANTAELLA, Lucia. A pós-verdade é verdadeira ou falsa? São Paulo: Estação das Letras e Cores, 2018.

SANTOS, Fábio Eulalio. A fundamentação da moral em Jürgen Habermas. Belo Horizonte: Universidade Federal de Minas Gerais, Faculdade de Filosofia e Ciências Humanas, 2007 (Dissertação, Mestrado em Filosofia).

SCHMITT, Carl. Teoria de la Constituicíon. Trad. Francisco Ayala. Madri: Alianza Editorial, 1996.

SUNSTEIN, Cass. Republic.com 2.0. Princeton: Princeton University Press, 2009.

VIANNA, Túlio Lima. Crítica da razão comunicativa: o direito entre o consenso e o conflito. Brasília: Revista de Informação Legislativa, 2008.

WOLLHEIM, Richard. As ideias de Freud. Trad. Álvaro Cabral. São Paulo: Círculo do Livro, 1971.

YEARS and Years. Direção: Lisa Mulcahy, Simon Cellan Jones. Produção: Russel T. Davies. Reino Unido e Irlanda do Norte: BBC One e HBO, 2019. 
Como citar este artigo: MACHADO, Luan Fernandes. Sobre a necessidade da moral na democracia. Revista de Ciências do Estado, Belo Horizonte, v. 7, n. 1, p. 1-19, 2022.

Recebido em 31.08.2021

Publicado em 21.02.2022

(cc) EY-NG-sa Atribuição-NãoComercial-CompartilhaIgual 4.0 Internacional 